\title{
Punishment or Policy Change: A Case of Plagiarism in a Dissertation
}

\author{
Patricia Deubel \\ Mansfield, Ohio
}

\begin{abstract}
This article examines a case of plagiarism in a dissertation, which was found after the doctoral degree had been awarded. Plagiarism detection is discussed in relation to the methodology, which included manual analysis, Google searches, and originality reports from Turnitin. Questions on the role of the dissertation committee, processes used to complete the dissertation, and consequences of plagiarism are addressed, as well as factors influencing a decision to report the case. Procedures for reporting plagiarism allegations and those the university used to investigate are included. Because this case illustrates that revoking a degree is not necessarily a sanction when plagiarism is proven, the article delves into legal issues surrounding policies for adjudicating allegations of academic misconduct and revoking degrees. Plagiarism prevention strategies are provided to illustrate the joint responsibility of a university, faculty, and students to prevent cases such as this one from ever happening. Universities are prompted to examine and uphold existing academic integrity and plagiarism policies and to develop appropriate policies for dealing with plagiarism if they do not exist.
\end{abstract}

Keywords: plagiarism, doctoral degree revocation, university policies, academic integrity, dissertation, plagiarism prevention

\section{Introduction}

Universities view academic integrity as integral to their missions and expect learners to complete all assignments to the highest ethical standards. They provide workshops, tutorials, writing centers, and digital resources, including for plagiarism detection, to help learners to write and cite appropriately. There are library and support services for faculty. One would expect that most if not all universities have policies in place addressing plagiarism. When plagiarism goes unnoticed in a doctoral dissertation and the degree has already been awarded, one has to wonder why this happened. What are the implications for all involved? Ultimately, would the degree be revoked? This article examines those questions using a case example of how one university addressed an instance of plagiarism and raises a number of policy issues. Strategies for preventing plagiarism are provided to illustrate the joint responsibility of a university, faculty, and students to prevent cases such as this one from ever happening. Every effort has been made in this article to protect the confidentiality of the institution and any persons involved.

\section{Identification of Plagiarism in the Case and in General}

A few years ago, I came across excerpts from a 2008 dissertation in Google Books, which included substantial, word-for-word content from an article I was very familiar with, but without proper attribution to the author throughout its use. My curiosity was piqued to determine the extent of plagiarism, so I obtained a copy of the full dissertation. After considerable time-consuming manual analysis, using Google searches and Turnitin originality reports, I was amazed to find entire passages taken from at least 21 other publications and websites without any attribution to those original authors either within text or in the reference list.

Please address queries to: Patricia Deubel, Independent Consultant, Mansfield, OH. Email: deubelp@neo.rr.com 
To support the methodology, Bretag and Mahmud (2009) indicated Turnitin reports have provided an excellent starting point for determining student plagiarism in their own practice and research. However, the "overall similarity index ... can potentially be deceptive and a high percentage of text match is not necessarily an indicator of any form of plagiarism" (p. 54). They concluded, "electronic detection in combination with manual analysis, nuanced academic judgement and clear processes provide the means to determine if plagiarism has occurred" (p. 57).

Turnitin (n.d.-a) itself recognizes an instructor must determine if text matches are plagiarism. As in this case, lifted content might be found in several sources, indicating a URL for a text match might not be the one a writer actually used. Such reports might not provide matches for all questionable content, implying further analysis is needed.

Although it is not within the scope of this article to elaborate on challenges to using plagiarism detection services, pedagogical and ethical issues have been raised, as well as legal issues resulting in court cases over student privacy rights and intellectual property. Educators desiring to use such services might consider implications of doing so, particularly in regard to academic integrity and relationships with learners (Gainer, 2013). Turnitin (2018) ensures privacy and security by encrypting data, using multiple data centers, redundant servers, firewalls, and audits. The security system has never been breached. Students retain copyright to papers submitted. Turnitin archives student papers, but institutions can opt out from this feature. Courts have held "archiving of student works in the educational context is a fair use" and "did not find that Turnitin's use of student works was in any respect unethical” (Turnitin, n.d.-b, para. 4).

Google can reveal potential occurrences of plagiarism, but it might take considerably more time to actually locate plagiarized sources (McCullough \& Holmberg, 2005). The Pennsylvania State University (Penn State, n.d.-a) included Turnitin and Google in its instructor guide for deterring and preventing plagiarism. It stated a search engine such as Google "is free and least likely to have negative legal consequences" (Using Google section).

Suspected plagiarism might also be found in "familiar passages and changes in voice, tone or emphasis" (Park, 2004, pp. 299-300) in the writing. A reviewer's vigilance and ability to recall or locate sources matter to ensure equitable treatment of students and to uphold academic standards. As reviewers' skills differ in detecting plagiarism, Park noted, "Digital detection is inevitably much quicker, easier and consistent than any human marker could ever hope to be" (p. 300). For example, some evidence in this case was gathered from documents archived within an organization's website or by using the Internet Archive (http://archive.org/web/).

It appeared the doctoral candidate knew to avoid secondary citations, as learners are encouraged to read and cite original sources. However, the candidate avoided doing that by lifting content from original documents and adding references associated with that content to the dissertation's reference list. Readers might view this as an attempt to fool the dissertation committee into believing numerous sources had been used for the literature review. At least 100 of 147 references were taken from those works of others. Although not necessarily considered plagiarism, APA errors led to finding citations within text for which no references were shown in the reference list and sources in the reference list that had not been cited.

Clues for detecting possible plagiarism included paragraphs without citations, lack of sources for numeric data, strings of citations from older publications that had no further content elaborations, content that did not appear to match the nature of the citation attributed to it, and quotes without exact locations from the source. There were instances in which the quote did not come from the cited source and word changes that misrepresented content from its source. 


\section{Questions and Concerns Raised in Analyzing the Dissertation}

Numerous questions and concerns arose as I analyzed the dissertation. Universities have procedures for completing the dissertation. However, the process apparently does not always work in practice or might be faulty to begin with. Primary questions centered on the dissertation committee itself, processes used to complete the dissertation, and whether or not the candidate had given thought to potential consequences of plagiarism.

To what extent should a committee bear responsibility for detecting plagiarism? This concern has merit. On one hand, academic integrity policies hold students responsible for appropriate citations and acknowledging sources. On the other hand, advisors are not only assisting learners, they are charged with upholding the integrity and reputation of the university. Their actions or inactions have potential consequences. For example, two faculty members at Ohio University who had advised graduate students whose theses contained plagiarism were recommended for dismissal. In multiple cases, they had "either failed to monitor the writing in their advisees theses or simply ignored academic honesty, integrity and basically supported academic fraudulence" (Meyer \& Bloemer, 2006, para. 1).

In this case, I wondered why the committee did not find any of what I found, considering that completing a dissertation is an iterative process. The committee apparently had the well-rounded expertise it needed. The committee approval process ensures members are active in research, have expertise in the dissertation topic, proposed methodology, and data analysis. There are several possible explanations. As mentorship involves considerable time and energy, committee members might have had too many mentees and insufficient time to pay close attention to details in iterations. They might have placed too much trust in the mentee to not plagiarize, perhaps considering that the dissertation was connected to the mentee's place of employment. However, as Park (2004) noted, a committee might not confront a student with plagiarism if advisors fear it might damage a mutual trust relationship and breed a Big Brother is watching atmosphere, which is not conducive to open discussion. Winchell (2013) suggested a professor might be well versed in his or her content area but lack sufficient knowledge about writing and citing sources or might not be perceptive enough to identify potential instances of plagiarism in student work.

Did the dissertation process require an annotated bibliography and using a plagiarism detection service? Harris (2015) recommended both strategies to prevent and deter plagiarism in research papers. The answers to both are "probably not." The 2002 dissertation guidelines, likely in effect in 2008, required proposals to include a bibliography, not specifically an annotated bibliography. However, a current list of best teaching practices to promote academic integrity, dating back to 2002, does include using an annotated bibliography in the writing process. Using plagiarism prevention software is not in that list.

Per Harris (2015), other than for historical development, was there a focus on using the most recent sources possible? For this 2008 technology-related dissertation, the answer would have been "no." Only about $15 \%$ of sources in the reference list were dated 2000 or later. The committee might have questioned whether or not the candidate actually read all 10 articles/books by the same author dating back to 1955 and five books by another dating back to 1960, which were in the reference list. It would have been reasonable to question why certain references on software design/selection were only listed in a parenthetical citation within text and not further elaborated upon. The committee might have questioned why there was only one research methodology reference, which was dated 1990 and cited only once following just a couple of sentences. The composition of an annotated bibliography might alert advisors to raise such concerns early in the dissertation process; requiring its use in writing might eliminate at least some problems with plagiarism. 
Committee members and the candidate might have benefited from a dissertation review checklist that also addressed plagiarism. Although the university provides multiple resources for completing the dissertation, it is unclear if such a checklist was available prior to 2008. Rice University's checklist (Hewitt, 2006) addresses plagiarism and is exemplary to illustrate content. Candidates can use it during the entire dissertation process and for a final check before submitting the completed report. It not only contains specific content, layout, and formatting required, it states the bibliography should contain "ALL the works cited" and "nothing that is not actually cited" (p. 2, Item 9). It makes clear that "plagiarism is an academic crime" and reminds candidates to "Make certain you have given author citations for all quotations, paraphrases, and borrowed or adapted visuals" (p. 3 , Item 15).

One way to encourage students to adhere to principles of academic integrity is to require them to sign a declaration that work submitted is their own and not plagiarized (Park, 2004). The College of Engineering and Computing at Nova Southeastern University (2016) included this declaration in its dissertation process for the idea paper, proposal, and final dissertation report. For this case, the university's academic integrity code, adopted in 2007, indicated faculty may ask learners for a signed statement confirming the submission adheres to the code. However, when submitting the final dissertation report, a candidate was required to sign a University Microfilms agreement on copyright compliance confirming the rights of others had not been violated.

Did the doctoral candidate think about consequences of plagiarism, if caught? Universities have revoked degrees for proven plagiarism (e.g., see cases in Fleming, 2016; Latourette, 2010; Pyle, 2010). Given that the university must prove plagiarism occurred, a candidate who plagiarizes might be willing to play Russian roulette (Park, 2004). Beyond a stain on personal integrity and compromising the integrity of the university, the bigger picture includes potential harm to employers by individuals who fraudulently obtained their degrees and use those credentials (Johnston \& Oswald, 1998).

Even if caught, degree revocation is not a foregone conclusion. Outside factors might influence sanctions, such as cultural differences in how plagiarism is viewed, the power and prominence of the accused, public interest in a case, the potential threat of a lawsuit from either a victim or the accused, and financial pressures (WriteCheck, n.d.). The following cases illustrate how consequences can differ.

Three years after she defended her dissertation, Lanegran (2004) discovered that a doctoral student submitted her dissertation as his own with minimal changes and was awarded a doctorate. Although her dissertation predated that of the plagiarist, she still needed to prove to the degree-granting university that the dissertation was actually hers. Her substantial evidence led to the doctorate being revoked. Subsequently, the plagiarist also lost the research position he had taken at a prominent university after being awarded the degree, as well as his reputation.

At the other extreme, Boston University confirmed that Martin Luther King Jr. plagiarized passages in his dissertation that led to his 1955 doctoral degree. Despite the confirmation, the investigative panel did not recommend revoking the degree because there was no point in doing so. It recommended a letter be put in the official copy of the dissertation, posted in the university library, stating its findings (Associated Press, 1991). Dissenters voiced the degree should have been revoked. One argued, "there was no statute of limitations on plagiarism. Neither death, nor Nobelity, nor immortality conferred immunity from the consequences of academic theft" (Luker, 2004, para. 3). 


\section{Factors Influencing a Decision to Report Plagiarism Allegations}

Those affiliated with a university would have a duty to report an allegation of plagiarism by one of its learners. I was not affiliated, so the decision was difficult to make. Shahabuddin (2009) indicated "lack of time, interest, or fear of consequences" potentially influence decision-making, but looking the other way at a plagiarist's unethical behavior "will encourage further plagiarism, and, as a result, the quality of professional research and publications will deteriorate" (p. 354).

Time was not a factor. I had a strong interest in an outcome but no desire to be involved in any litigation stemming from a respondent's retaliation. Thus, to be confident in any allegations, I spent the time to gather substantive, documented evidence to ensure the university would investigate.

I considered perspectives from others who mentor doctoral learners. In my 2015 conversations with three respected scholars, they stated, "Let me give you my advice, which I don't agree with. Let it go. Life's too short to take on the aggravation." "I've had my own articles plagiarized, but you can't win-I doubt the Dean would even read your observations, but he'd be obligated to act on evidence like turnitin.com." "Wow...this could affect the university's accreditation."

Ultimately, the decision to report the allegation stemmed from my beliefs after having taught in a doctoral program for several years and as an educator for over 40 years. Plagiarism within the dissertation undermines the dissertation process itself, the merit of the dissertation for those who might use its results, and the value of the doctorate from the degree-granting university.

\section{Reporting Plagiarism Allegations}

Each university has its own process for reporting allegations of plagiarism. I contacted the successor to the dean who signed the dissertation, as that dean was no longer available. In a succinct email, I indicated how the discovery was made and provided a quick overview of findings, the process used for discovery, and beliefs as to why I was bringing the case to his attention. Following his instructions, 25 files were submitted to the university, including plagiarized articles, extensive highlighted text and comments in the dissertation itself, a summary document of the plagiarism found, and a Turnitin report.

\section{Investigative Procedures}

Policies and procedures for investigating allegations of plagiarism might be in documents referring to academic misconduct, research misconduct, or scholarly misconduct (e.g., see Oregon State University, 2006; Penn State, 2015; Yale University, n.d.). Such examples are easily found using Google. These latter universities have similar procedures as used in this case. The dean initiated an investigation and forwarded allegations to the university's research department. An inquiry committee was formed to determine if allegations had merit. As they did, the university convened a second committee to formally investigate those. The respondent was provided due process. In general, a complainant may be interviewed. The investigation committee creates a report of its findings, identifies who was responsible, and level of seriousness. The committee also identifies publications that may need to be corrected or retracted, and may recommend sanctions. The complainant will receive results from the inquiry and investigation committees. Ultimately, findings go to the provost or designee, who will finalize any sanctions and report results to the respondent, complainant, and appropriate university officials. 


\section{The Resolution}

The university took a full year to resolve this case. The investigation committee found multiple occurrences of plagiarism, including

a significant number of lengthy paragraphs ... lacking a critical review of the literature, some of which lack[ed] the appropriate citations and references. On multiple occasions within these paragraphs, only one word [had] been changed as compared to the corresponding paragraphs in the original publications. In addition, parts of the list of references appear[ed] to be copied directly from the seminal articles.

The research misconduct was "serious in nature."

However, the committee recommended that the degree holder's actions "did not merit" revoking the degree, even though the resolution clearly stated, "Plagiarism diminishes the research integrity of the investigator, the doctoral program at the university, and violates the rights and intellectual property of the authors of the original source material." In his final report, the provost stated the respondent was "required to modify" the dissertation to remove the plagiarism. Until then, the dissertation would be removed from ProQuest and the university's digital repository. Surprisingly, there was no time limit set to comply, nor further indication of consequences should the respondent not comply. Hence, the only sanction was removing the dissertation from key databases. The person still has a doctorate and all benefits associated with it, so why put forth that effort?

To better understand this resolution, the vice provost for research claimed the university had no policy in place at the time to revoke a degree for research misconduct, or they could not find one and would be developing such a policy. The university and respondent had consulted legal counsel. The sanction he recommended to the provost was based on a prior similar case in which the respondent was offered an opportunity to correct and resubmit the dissertation. However, he also indicated the respondent in this case most likely would not revise (vice provost, personal communication, March $18,2016)$.

\section{Legal Issues}

Park (2004) stated that "Extreme sanctions, such as ... withdrawing a degree award, inevitably require careful application of watertight procedures and often give rise to legal disputes" (p. 301). In my January 2018 communication with a former president of two U.S. universities, he indicated a university's insurance company plays a major role in litigation when it "indemnifies" or pays for covering expenses and settlements, if the university is threatened with litigation. The insurance company can "force" a settlement regardless of the merits of the case, and often does. So an institution might find itself unable to enforce especially stringent sanctions. A university might also consider its tuition money might be better spent elsewhere, so a lesser sanction than it would have preferred might be considered to resolve a case and avoid costs, time, and inconveniences associated with a legal dispute.

The question remains as to how a decades-old university could not have a policy applicable to this case. Latourette (2010) outlined several concerns a university would have adjudicating allegations of plagiarism. It must "have in place an academic policy and procedures on all forms of academic dishonesty." Plagiarism must be clearly defined, including "whether intent is required." The university must "adhere to standards enunciated in the policy" and afford respondents "the due process requirements of the Fourteenth Amendment, if it is a public institution, or fundamentally fair procedures, if it is a private institution" (pp. 55-56). The latter means providing "at least the same basic protections" as those required in public settings (Johnston \& Oswald, 1998, p. 84). 
Further, "Educational institutions that interpret and enforce their plagiarism policies are expected to do so in accordance with procedures established in student and faculty handbooks" (Mawdsley, 2009, p. 254).

The latest revision of the university's academic integrity policy went into effect in the fall of 2007 . As this was before the degree in question had been awarded, the candidate should have been aware of it. Students are held responsible for documenting and acknowledging sources. Violations include plagiarism, defined as representing someone else's words, ideas, or work as one's own without attribution. Intent is not included. The code states violations will be treated seriously. Penalties include the catch-all "other sanctions as appropriate." Although revoking a degree is not among examples, catch-all language enables a university "to tailor the appropriate remedy to the degree of materiality and culpability of the false information and individual student" (Johnston \& Oswald, 1998, p. 73). Procedures for adjudicating violations are stated. The latter suggests the university might have applied this policy to the case. Not only is the academic integrity code posted on its website, but it also appeared within the student handbook.

Unfortunately, universities differ in how plagiarism is defined and whether or not intent is included. The volume of plagiarism might infer a writer's intent; however, no math formula exists to quantify it. Possible sanctions also differ (Latourette, 2010). To illustrate, plagiarism within the academic integrity code at the University of North Carolina-Charlotte (2017) is "intentionally or knowingly presenting the work of another as one's own" (III. Definitions of Violations, Section D). Sanctions clearly state degree revocation is possible for falsification found in dissertations.

Courts have held universities and colleges can revoke academic degrees owing to fraud (Latourette, 2010). Per Standler (2012), plagiarism is fraud. Victims include "a faculty committee that unknowingly receives a plagiarized thesis or dissertation" and "a college or university that unknowingly issues a passing grade or diploma to a plagiarist" (p. 33). For a resolution, Standler included the "plagiarist forfeiting any credit, reward, benefit, or diploma that was "earned" with the plagiarized work" (p. 33).

Plagiarism is an ethical and moral offense, and per courts, it is best dealt with by the university, which has the expertise regarding academic misconduct. Universities strive to do this quietly (Latourette, 2010). What might have happened if the university had revoked the degree, resulting in litigation?

Two views have emerged when courts become involved: a university's authority to revoke a degree and its right based on contract law (Johnston \& Oswald, 1998). First, in discussing Hand $v$.

Matchett, Mawdsley (2009) stated,

in the absence of specific state requirements like those in Hand, courts generally recognize that university officials have the inherent authority to revoke an improperly awarded degree where the university is acting pursuant to granted authority to confer degrees and to take any action necessary to maintain the university. (p. 258)

Second, in cases of deliberate fraud,

courts have found a justification for degree revocation in contract law: By the university's contract with the student, the degree was awarded only because of the fulfillment of certain academic requirements. If these requirements were in fact not fulfilled, no degree should have been issued, and the degree can therefore be revoked. (Silverglate \& Gewolb, 2014, p. 68) 
Contract law applies to public and private institutions (Johnston \& Oswald, 1998). In summary, as long as a university carried out its adjudication process without "capricious behavior" and employed due process as a public institution or its equivalent at a private institution, courts will generally uphold a university's decision regarding plagiarism (Latourette, 2010, p. 87).

\section{Significance of This Case}

This case illustrates that revoking a degree does not necessarily happen in cases of proven plagiarism within a dissertation. It illustrates the university, dissertation committee, and doctoral candidate all played a role in what happened. The university claimed to have no research policy to deal with the case, but perhaps it did in light of its academic integrity policy. Although it may have been fooled, the committee appeared to not fulfill its responsibilities to uphold the university's principles of academic integrity in reading the dissertation. The candidate began the entire problem by plagiarizing content of others.

There was never an intention for this case to lead to a change in university policy, but that eventually happened. The university followed through to develop a formal policy for revoking degrees. The questions and concerns I raised in my analysis, the resolution itself, and the follow-up discussion with the vice provost for research confirm that plagiarism prevention involves all parties: the university, faculty, and students.

\section{Plagiarism Prevention Strategies}

A policy on plagiarism and its consequences can clearly influence how students perceive its seriousness. Guidelines can be developed that define plagiarism, provide examples of it, explain why plagiarism is unacceptable, list methods to detect it, and include appropriate penalties that will be applied for each occurrence. Guidelines might also state they are needed to "ensure consistency across the university and fairness to students" (Park, 2004, p. 296). The policy and guidelines should be "widely disseminated" (p. 295).

Hewitt's (2015) document, Plagiarism: Recognize and Avoid It, includes such guidelines. It would be a useful model for dissertation mentors and mentees and to include among course resources. Her plagiarism definition contains a multimedia element: "Plagiarism is the use of someone else's ideas, processes, results, equipment design, visuals, wording, or even sentence structure as if they were your own, whether the source is printed or electronic" (p. 1). She elaborated on the importance of avoiding plagiarism, how to do so, and advised graduate students to keep electronic notes on each resource read. Citation examples, examples of plagiarizing and paraphrasing, and answers to frequently asked questions were also provided.

Hewitt's (2015) definition suggested guidelines and tutorials for preventing plagiarism should also address copyright and fair use of media, as there are limitations on the amount of copyrighted material that can be used without permission. Such material includes motion media, text, music, lyrics, music videos, illustrations, photographs, and numerical data sets (Deubel, 2005). Southern Illinois University at Carbondale (n.d.) provided an online copyright tutorial, which included quizzes and cases designed to test practical knowledge. When submitting a dissertation to the University of Texas at Austin Graduate School (n.d.), students must provide proof of having completed its copyright tutorial with a $100 \%$ score, thus emphasizing its importance.

Brown and Janssen (2017) recognized that in spite of university policies and guidelines for preventing plagiarism, students' ethical and moral perspectives influence their behaviors in relation to adhering to those (p. 102). For a practical approach to preventing plagiarism, they designed a 2 -hr intervention to use in a classroom environment. Students learn types of plagiarism, then paraphrase 
a one-page document avoiding plagiarism. The workshop includes real cases illustrating plagiarism's impact, guided discussions on plagiarism detection software, experiences from panels, and practice using Turnitin. Students write their own academic integrity code, "a pledge based around reasons for not plagiarizing" (p. 104). To conclude the workshop, students reflect on statements about plagiarism to decide if each is true or false. Pairs then discuss their responses before discussion moves to the group. Data reveal the intervention has decreased the number of cases of confirmed plagiarism in their university program.

Per Brown and Janssen (2017), their workshop can be adapted for use at all levels of students and courses. Online plagiarism prevention workshops also exist, such as the one provided by the library at the University of South Carolina Upstate (n.d.). In addition to issuing warning letters among penalties for first and second occurrences of confirmed plagiarism (Park, 2004), students might be required to take part in such an intervention. New doctoral students would benefit from a plagiarism prevention workshop in orientation activities.

Requiring specific components (e.g., minimum number of references, journals, books, interviews), setting due dates for various steps required for completing research, using an annotated bibliography, requiring most references to be up to date, and oral reporting are among strategies for preventing plagiarism in research papers. Instructors might pose questions in a subtle manner regarding suspicious content and citations (e.g., "Can you tell me more about ...?") to reveal plagiarism without actually making outright accusations (Harris, 2015). The latter should be included in the dissertation process.

Penn State's (n.d.-b) instructor guide on plagiarism included Harris's (2015) strategies among others. A statement on academic integrity, included in a syllabus, highlights its importance. Instructors might ask students to sign a contract, submit reference lists and drafts throughout the writing process, and submit research notes with final drafts. Instructors are advised to tell students ahead of time if their work will be submitted to a plagiarism detection service or software package. That knowledge alone might decrease instances of plagiarism.

Multiple software options for detecting plagiarism should be provided in faculty and student resources if a university has not licensed a service. Only one software option is listed among resources for preventing plagiarism at the university in this case. Faculty and students might not use it owing to its design limitations. The developer acknowledges that his free software is Windowsbased, not designed to search the web to find matching documents for a user, and can handle only a limited number of file formats. Before recommending or purchasing software, potential users should vet it. Deubel (2005) recommended examining software for its "reliability, technical requirements, ease of use, cost, and stability of the vendor" (p. 8). Software should include a tutorial for how to use it and interpret results.

\section{Concluding Remarks}

This case should never have happened. Having policies in place for academic misconduct is one issue, but actually enforcing them is another. Policies containing a ladder of penalties for plagiarism associated with first, second, and additional occurrences help university students as they gain writing skills. Although proving intent beyond a reasonable doubt is difficult, willful cheating and deception at the highest level "must be dealt with robustly" (Park, 2004, p. 301). What does robust mean? Would a sanction be considered robust if it only entailed removing the dissertation from as much public access as possible, even though the plagiarism within it was deemed significant and serious in nature, as in this case? Because the dissertation is the culminating experience in obtaining the doctorate, should not the policy reflect "zero tolerance" (p. 302) for willful plagiarism, as Park suggested, even if the discovery is made after the degree has been awarded? When is it 
beneficial to revoke a degree or not? Is it really a matter of upholding the reputation and integrity of a university in its decision-making process, or is it willingness to compromise the same when litigation and money are at stake? Going forward, these questions need answers.

Penn State recognized the seriousness of plagiarism in a dissertation in a 2016 memo to graduate staff and students (Fleming, 2016) regarding its decision to revoke a research doctorate. The memo is significant in pointing out "the core philosophy behind scholarly research" (i.e., pursuit of knowledge, truth, understanding) and "if we compromise these for any reason then we fail at the very core of what it means to be scholars" (Memo, p. 2, in Fleming, 2016). Penn State's memo also echoes a strong statement in Mawdsley (2009): "Those who take shortcuts and steal the work of others without appropriate attribution should expect to face condemnation and attendant penalties that come with the finding of such theft" (p. 267).

If universities expect to maintain credibility and have policies on academic integrity, including sanctions for violations, then they must uphold those standards. Policies should include the right to rescind a degree or change its classification after being awarded owing to plagiarism. Policies should be open, transparent, fair, and consistently applied. Participants should know their roles and responsibilities (Park, 2004). If research policies need to be developed or updated, it is time to do so. Otherwise, there are no disincentives to plagiarism. However, policies alone will not prevent cases like this one from ever happening without all participants taking a proactive approach to preventing plagiarism in the first place by using strategies suggested herein. The "copy/paste" culture will continue to rise, and those who discover plagiarism will not report it.

\section{References}

Associated Press. (1991, October 11). Boston U. panel finds plagiarism by Dr. King. The New York Times. Retrieved from https://www.nytimes.com/1991/10/11/us/boston-u-panel-findsplagiarism-by-dr-king.html

Bretag, T., \& Mahmud, S. (2009). A model for determining student plagiarism: Electronic detection and academic judgement. Journal of University Teaching \& Learning Practice, 6, 49-60. Retrieved from https://eric.ed.gov/?id=EJ867296

Brown, N., \& Janssen, R. (2017). Preventing plagiarism and fostering academic integrity: A practical approach. Journal of Perspectives in Applied Academic Practice, 5, 102-109. Retrieved from https://jpaap.napier.ac.uk/index.php/JPAAP/article/view/245/pdf

Deubel, P. (2005). Plagiarism: Prevention is the name of the game. English Leadership Quarterly, 28, 6-11.

Fleming, M. (2016, March 2). Graduate school revokes doctorate for plagiarism. Retrieved from http://onwardstate.com/2016/03/02/graduate-school-revokes-doctorate-for-plagiarism/

Gainer, K. (2013). Plagiarism detection services: Unsettled questions. Urbana, IL: National Council of Teachers of English, Conference on College Composition and Communication, Intellectual Property Report. Retrieved from http://cccc.ncte.org/cccc/committees/ip/plagiarismdetection

Harris, R. (2015, May 18). Anti-plagiarism strategies for research papers. Retrieved from https://www.virtualsalt.com/antiplag.htm

Hewitt, J. (2006). Thesis/dissertation checklist. Houston, TX: Rice University. Retrieved from http://www.owlnet.rice.edu/ cainproj/writingtips/thesischecklist.pdf

Hewitt, J. (2015). Plagiarism: Recognize and avoid it. Houston, TX: Rice University Center for Engineering Leadership. Retrieved from http://gpsdocs.rice.edu/orientation/Plagiarism_Hewitt_document.pdf 
Johnston, R. G., \& Oswald, J. D. (1998). Academic dishonesty: Revoking academic credentials. The John Marshall Law Review, 32, 67-85. Retrieved from http://repository.jmls.edu/lawreview/vol32/iss1/6

Lanegran, K. (2014, July 2). Fending off a plagiarist. The Chronicle of Higher Education. Retrieved from https://www.chronicle.com/article/Fending-Off-a-Plagiarist/44680

Latourette, A. W. (2010). Plagiarism: Legal and ethical implications for the university. The Journal of College and University Law, 37, 1-91.

Luker, R. (2004, December 21). On Martin Luther King's plagiarism [Blog post]. Retrieved from https://historynewsnetwork.org/blog/9172

Mawdsley, R. (2009). The tangled web of plagiarism litigation: Sorting out the legal issues. Brigham Young University Education and Law Journal, 2009, 245-267. Retrieved from http://digitalcommons.law.byu.edu/elj/vol2009/iss2/3/

McCullough, M., \& Holmberg, M. (2005). Using the Google search engine to detect word-for-word plagiarism in master's theses: A preliminary study. College Student Journal, 39, 435-441.

Meyer, G., \& Bloemer, H. (2006, May 30). Plagiarism in the department of mechanical engineering in the Russ College of Engineering at Ohio University [Media release]. Retrieved from https://www.ohio.edu/outlook/media/BMIR.cfm

Nova Southeastern University. (2016). The dissertation guide: A guide for CEC doctoral students. Retrieved from https://cec.nova.edu/doctoral/documents/diss_guide.pdf

Oregon State University. (2006). Scientific and scholarly misconduct: Oregon State University procedures for handling allegations of research misconduct. Retrieved from https://research.oregonstate.edu/ori/scientific-and-scholarly-misconduct

Park, C. (2004). Rebels without a clause: Towards an institutional framework for dealing with plagiarism by students. Journal of Further and Higher Education, 28, 291-306. Retrieved from http://www.lancaster.ac.uk/staff/gyaccp/rebels\%20without\%20a\%20clause.pdf

Pyle, E. (2010, September 15). Plagiarism a persistent problem on campuses. The Columbus Dispatch. Retrieved from http://www.dispatch.com/content/stories/local/2010/09/15/plagiarism-a-persistent-problemon-campuses.html

Shahabuddin, S. (2009). Plagiarism in academia. International Journal of Teaching and Learning in Higher Education, 21, 353-359. Retrieved from http://www.isetl.org/ijtlhe/pdf/IJTLHE641.pdf

Silverglate, H. A., \& Gewolb, J. (2014). FIRE's guide to due process and campus justice. Philadelphia, PA: Foundation for Individual Rights in Education. Retrieved from https://www.thefire.org/first-amendment-library/special-collections/fire-guides/fires-guide-todue-process-and-campus-justice/

Southern Illinois University at Carbondale. (n.d.). Copyright basics online course. Retrieved from http://www.lib.siu.edu/copyright/

Standler, R. (2012). Plagiarism in colleges in USA: Legal aspects of plagiarism, academic policy. Retrieved from http://www.rbs2.com/plag.pdf

The Pennsylvania State University (Penn State). (n.d.-a). Detecting plagiarism. Retrieved from http://tlt.psu.edu/plagiarism/instructor-guide/detecting-plagiarism/

The Pennsylvania State University (Penn State). (n.d.-b). Plagiarism detection and prevention: An instructor guide. Retrieved from http://tlt.psu.edu/plagiarism/instructor-guide/ 
The Pennsylvania State University (Penn State). (2015). RP02 Addressing allegations of research misconduct. Retrieved from https://policy.psu.edu/policies/rp02

Turnitin. (n.d.-a). Interpreting the similarity report. Retrieved from https://guides.turnitin.com/01_Manuals_and_Guides/Instructor_Guides/Feedback_Studio/19_ The_Similarity_Report/Interpreting_the_Similarity_Report

Turnitin. (n.d.-b). Legal FAQs. Retrieved from http://turnitin.com/en_us/privacy-center/legal-faqs

Turnitin. (2018). Privacy and security. Retrieved from https://guides.turnitin.com/Privacy_and_Security

University of North Carolina-Charlotte. (2017). Code of student academic integrity. Retrieved from https://legal.uncc.edu/policies/up-407

University of South Carolina Upstate. (n.d.). Plagiarism prevention workshop: Home. Retrieved from https://uscupstate.libguides.com/PlagiarismPrevention

University of Texas at Austin Graduate School. (n.d.). Copyright tutorial. Retrieved from https://gradschool.utexas.edu/academics/theses-and-dissertations/doctoralcandidacy/copyright-tutorial

Winchell, B. (2013, April 11). Successful plagiarism 101. The Chronicle of Higher Education. Retrieved from https://www.chronicle.com/article/Successful-Plagiarism-101/138413

WriteCheck. (n.d.). The aftermath of plagiarism. Retrieved from http://en.writecheck.com/theaftermath-of-plagiarism/

Yale University. (n.d.). Dealing with allegations of academic misconduct. Retrieved from https://provost.yale.edu/policies/academic-integrity/dealing-allegations-academic-misconduct

The Journal of Educational Research and Practice provides a forum for studies and dialogue that allows readers to better develop social change in the field of education and learning. Journal content may focus on educational issues of all ages and in all settings. It also presents peer-reviewed commentaries, book reviews, interviews of prominent individuals, and additional content. The objectives: We publish research and related content that examines current relevant educational issues and processes aimed at presenting readers with knowledge and showing how that knowledge can be used to impact social change in educational or learning environments. Additional content provides an opportunity for scholarly and professional dialogue regarding that content's usefulness in expanding the body of scholarly knowledge and increasing readers' effectiveness as educators. The journal also focuses on facilitating the activities of both researcher-practitioners and practitioner-researchers, providing optimal opportunities for interdisciplinary and collaborative thought through blogging and other communications.

Walden University Publishing: http://www.publishing.waldenu.edu 